\title{
The Study of Inhibition Effect of Rhenium Thioacetic and Dithiocarbonic Acids in Oxidation Reaction
}

\author{
Fakhriyya M. Nasiri'1, Fikret A. Kuliev ${ }^{2 *}$, Arif J. Efendy ${ }^{1}$, Lyudmila I. Kojarova ${ }^{1}$, \\ Farida A. Abdullayeva1, Irada H. Melikova', Natevan F. Aykan' \\ ${ }^{1}$ Institute of Catalysis and Inorganic Chemistry Named after Academician M.F.Nagiyev of Azerbaijan, Baku, \\ Azerbaijan \\ ${ }^{2}$ Azerbaijan Medical University, Baku, Azerbaijan \\ Email: mmanafov@gmail.com
}

Received 9 June 2015; accepted 5 July 2015; published 9 July 2015

Copyright (C) 2015 by authors and Scientific Research Publishing Inc.

This work is licensed under the Creative Commons Attribution International License (CC BY).

http://creativecommons.org/licenses/by/4.0/

c) (i) Open Access

\begin{abstract}
Antioxidant activity of interaction products of the studied compounds with tret-Butyl hydroperoxide is studied. New, more active acceptors of free radicals are formed in the process of oxidative transformations of initial compounds. It is investigated that the products have high inhibiting properties. The parameter $f k$, characterizing inhibitory effect of an inhibitor is studied.
\end{abstract}

\section{Keywords}

Synthesis, Phenylthioacetic and Dithiocarbonic Acids, Hydroperoxide, Inhibitor

\section{Introduction}

One of the main characteristics of organic substances is their stability against thermal-oxidative degradation. Stabilizers, antioxidants, oxidation inhibitors, antioxidant additives are added into the substances to increase the stability.

There are hundreds of substances with antioxidant (inhibiting) effect. However, only the very few substances find practical application. Mainly they are alkylated ohenols, aromatic amines, sulfur- and phosphor containing organic substances [1].

Substances synthesized as oxidation inhibitors, as a rule, undergo long-term, expensive tests, which significantly increase their costs. In this regard, studying the kinetics and mechanism of effects of these substances is relevant and allows us to develop scientific bases for detecting and purposefully synthesizing the most optimum

*Corresponding author.

How to cite this paper: Nasiri, F.M., Kuliev, F.A., Efendy, A.J., Kojarova, L.I., Abdullayeva, F.A., Melikova, I.H. and Aykan, N.F. (2015) The Study of Inhibition Effect of Rhenium Thioacetic and Dithiocarbonic Acids in Oxidation Reaction. Advances in Chemical Engineering and Science, 5, 338-344. http://dx.doi.org/10.4236/aces.2015.53035 
structures of new organosulfur oxidation inhibitors.

The substances synthesized as oxidation inhibitors generally pass long-term, expensive testing that considerably increases their cost. In this connection, the study of antioxidant effect of dithiocarbamate $\left(A_{1}\right)$ and thioamide $\left(\mathrm{A}_{2}\right)$ during oxidation of hydrocarbons is important.

Dithiocarbamate and thioamide can be used as selective homogeneous catalysts of ion decay.

\section{Experimental Part}

Qualitative and quantitative analyses of decay products of cumyl hydroperoxide are conducted by method of chromatographic analysis on universal chromatograph (LChM-80). Acidity of interaction reaction products of cumyl hydroperoxide with dithiocarbamate and xanthogenates was determined by alkyl meter method.

Objects of researches were synthesized by the known method [2]:

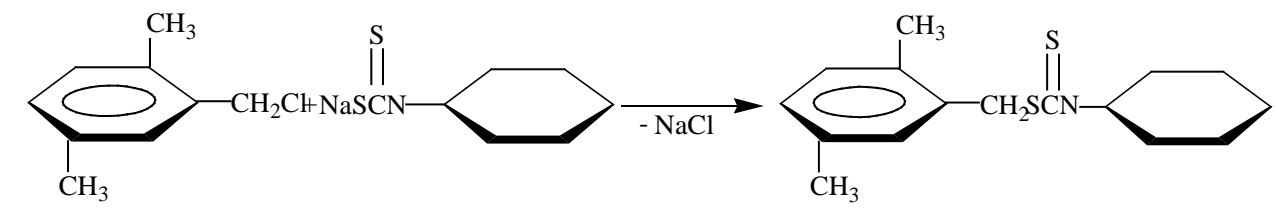

S-(2.5-dimethylbenzyl)piperidinodithiocarbamate

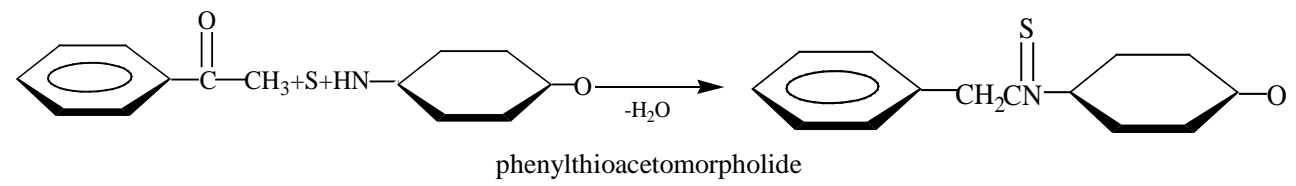

Consumption rate of oxygen was determined from the formula:

$$
W_{\mathrm{O}_{2}}=6.21 \times 10^{-9} \frac{P \Delta H}{V \Delta t} \mathrm{~mol} / \mathrm{l} . \mathrm{sec}
$$

where $P$ —oxygen tension in the system (mm. rt. st); $V$-volume of the reaction solution (ml); $\Delta H=H_{0}-H_{1}-$ height of mercury column at the moment of time $t_{0}$ and $t$ correspondingly; $\Delta t=t_{0}-t$ (min.).

At constant $P=760 \mathrm{~mm}$ rt. st and $V=2 \mathrm{ml}$

$$
W_{\mathrm{O}_{2}}=2 / 36 \times 10^{-6} \frac{\Delta H}{\Delta t} \mathrm{~mol} / \mathrm{l} \text {. sec }
$$

In deriving these formulas, it was considered that temperature of gas in burette $298 \mathrm{~K}$ and $H=1.1 \mathrm{~mm}$-correspond to the consumption of $0.01 \mathrm{ml}$ oxygen.

\section{Results and Discussion}

As model hydrocarbons for estimation of inhibition effect of thiocarbonyl compounds $\left(A_{1}, A_{2}\right)$ we used isopropylbenzene and ethylbenzene, i.e. easy oxidizing alkylaromatic hydrocarbons, oxidation mechanism of which are reliably established and quantitatively studied [3] [4]. Azobisisobutyronitrile (AIBN) was used as an initiator. Inhibition effect of thiocarbonyls on oxidation of isopropylbenzene and ethylbenzene was studied by kinetics of oxygen absorption in the mode of auto oxidation and oxidation with initiator. Oxygen absorption was measured on manometric unit at 333 and $383 \mathrm{~K}$ and $P_{\mathrm{O} 2}=100 \mathrm{kPa}$.

Kinetic curves of oxygen absorption in initiated oxidation of hydrocarbon were worked out by the following way: initial rate of oxygen absorption $W_{0}$ were measured in the presence of inhibitor. Later on the formula was used [5] [6]:

$$
W_{O}=\frac{k_{2}[R H] W_{i}}{f k[\text { Ing }]}+W_{i}-W_{N_{2}},
$$

where $W i=k_{i}$ [AIBN]; $k_{i}$-constant of initiation rate (for AIBN at $333 \mathrm{~K}_{i}=1 \times 10^{-5} \cdot \mathrm{C}$ ); $k_{2}$-reaction constant of continuation of chain $\mathrm{RO}_{2}+\mathrm{RH}$ (for isopropylbenzene) at $333 \mathrm{~K}$ is $1.5 \mathrm{l} \mathrm{mol} / \mathrm{c}$ ); [RH] concentration of oxi- 
dizing hydrocarbon (for isopropylbenzene at $333 \mathrm{~K}$ is 7.17); [lng]—concentration of inhibitor; $W_{N_{2}}$-gas emission correction during AIBN decay $\left(W_{N_{2}} \frac{W_{i}}{2 l}\right)$, where $l$-yield of radicals in volume, is 0.6 at $333 \mathrm{~K}$ in chlorbenzene and isopropylbenzene; $f$-stoichiometric coefficient of inhibition, is equal to oxidation chain numbers broken in one molecule of inhibitor and products of its conversion; $k$-reaction rate constant $\mathrm{RO}_{2}^{\bullet}$ with inhibitor.

From here the parameter $f k$ is equal to

$$
f k=\frac{k_{2}[R H] W_{i}}{\left[W_{O}-W_{i}+W_{N_{2}}\right][I n g]}
$$

Parameter $f k$ characterizes inhibitory anti-radical activity of inhibitor lng. In some cases we used the method of transformation of kinetic curves of oxygen absorption to calculate $f k$ by formula:

$$
\left[\Delta \mathrm{O}_{2}\right]^{-1}=\alpha \frac{[\mathrm{Ing}]}{W_{i} \Delta t}
$$

where $\quad \alpha=f \frac{k}{k_{2}[R H]}$; the value $f k$ can be calculated by the slope of this line.

During auto oxidation of hydrocarbons in the presence of $A_{1}, A_{2}$ it was established that these substances notably differ on ability to slow down the process. Dithiocarbamate $\left(A_{1}\right)$ shows properties of an antioxidant at concentrations $10^{-3}-10^{-4} \mathrm{~mol} / \mathrm{l}$ (Figure 1 and Figure 3). It should be noted that kinetic curves of oxygen absorption at oxidation of isopropylbenzene and ethylbenzene differs. In particular, after induction period oxidation of ethylbenzene goes with autoacceleration, in case of isopropylbenzene this will be preceded by S-type curve with auto-deceleration. At first inhibited oxidation rate of isopropylbenzene is slightly higher, but further long-term braking takes place.

Partial prooxidant effect observed in the early stage of oxidation of isopropylbenzene with $A_{1}$ (Figure 1, curve 2) can be due to reactions of dithiocarbamate with cumyl peroxide radicals $\left(R O_{2}^{*}\right)$ or cumyl hydroperoxide (CHP) formed during oxidation. It is shown that the first slow stage of the reaction $\mathrm{A}_{1}$ with CHP is homolytical. The higher initial rate of autooxidation of isopropylbenzene with $A_{1}$ may result from the initiation by the reaction
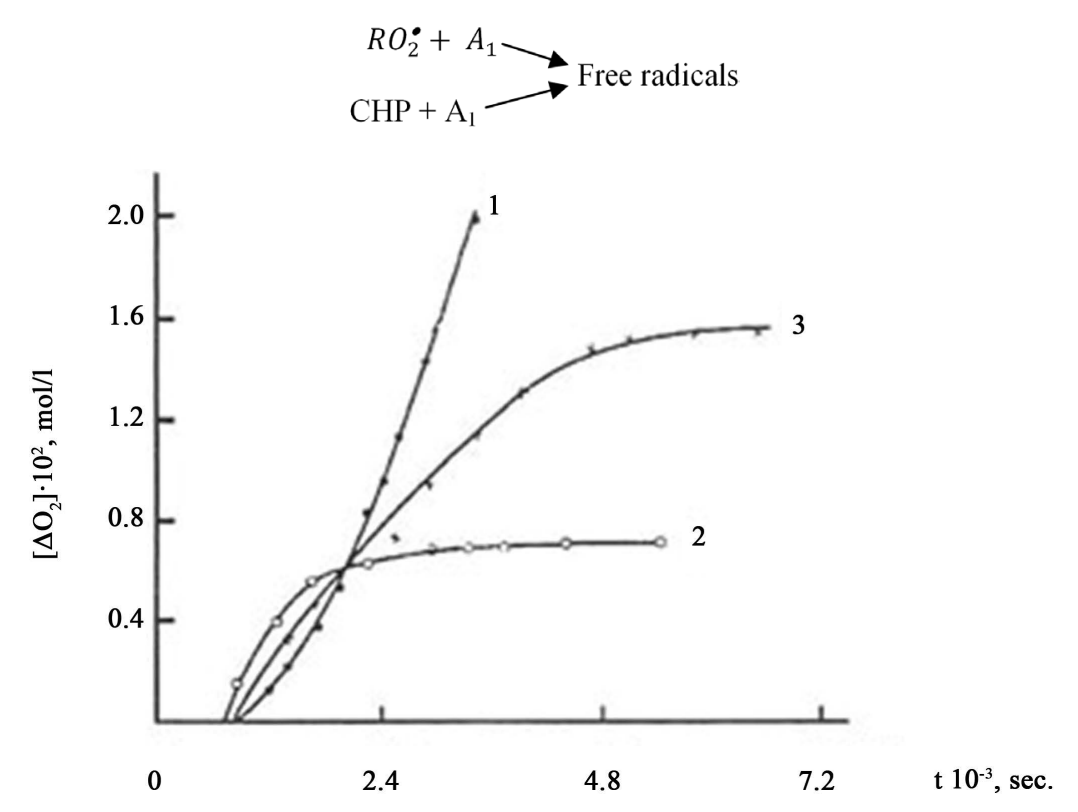

Figure 1. Kinetic curves of autooxidation of isopropylbenzene with the presence of $A_{1}$ : lwithout inhibitor; $2-\left[A_{1}\right]=4 \times 10^{-3} \mathrm{~mol} / \mathrm{l} ; 3-\left[A_{1}\right]=5 \times 10^{-4} \mathrm{~mol} / \mathrm{l} ; \mathrm{T}=383 \mathrm{~K} ; P_{\mathrm{O} 2}=100 \mathrm{kPa}$. 
Hereafter, as CHP accumulates, when its concentration exceeds inhibitor concentration, oxidation rate sharply reduces and long-term braking occurs. Such braking may result from "secondary" braking action, i.e. action of products $(P)$ of oxidative transformations $A_{1}$.

For quantitative estimation of inhibition effect of dithiocarbamate $\left(A_{1}\right)$ we studied initiated oxidation of ethylbenzene with its presence (Figure 2). Braking of oxidation occurs at sufficiently high concentrations $\left[A_{1}\right] \geq$ $1 \times 10^{-2} \mathrm{~mol} / \mathrm{l}$, initial rate of oxidation with $A_{1}$ is not very different from the rate of uninhibited oxidation. This did not allow us to calculate the value of parameter $f k$ for dithiocarbamate $\left(A_{1}\right)$. However, the obtained results are sufficient for conclusion on low inhibitory antiradical activity of $A_{1}$.

Thioamide $\left(A_{2}\right)$ has the highest inhibition properties among the studied substances. It acts as a brake on initiated oxidation of isopropylbenzene at concentrations $3 \times 10^{-3}-1 \times 10^{-2}$ (Figure 3, Table 1).

The distinctive feature of inhibition action of thioamide $\left(A_{2}\right)$ is that from the beginning oxidation rate of isopropylbenzene is slightly below than the uninhibited one. Nevertheless, during inhibition of oxidation with thioamide (Figure 3 ) its inhibitory properties increase, i.e. oxidation rate decreases at time interval (80 min). It shows that from thioamide by the reaction:

$$
\mathrm{A}_{2}+\mathrm{RO}_{2}^{\cdot} \rightarrow P_{\mathrm{A} 2}
$$

stronger acceptor (or acceptors) of peroxide radicals are formed $P_{A 2}$.

Thioamide $\left(A_{2}\right)$ and thiocarbamate $\left(A_{1}\right)$ have the highest inhibition properties among the studied substances. Thiocarbamate $\left(A_{1}\right)$, thioamide $\left(A_{2}\right)$ were oxidized by tret-Butyl hydroperoxide at $373 \mathrm{~K}$ in chlorobenzene in inert atmosphere (nitrogen, $[\mathrm{ROOH}]_{0}=0.2 \mathrm{~mol} / \mathrm{l},\left[A_{1}\right]_{0}=4 \times 10^{-3} \mathrm{~mol} / \mathrm{l}$ ). Such oxidation reaction takes place rather quickly. The decay of hydroperoxide was performed until its full decay. Concentration of hydroperoxide was controlled by iodometry. The solution inside reactor was used in further experiments.

Selection of TBHP as an oxidizer was due to that first, it easily oxidizes thiocompound and decomposes itself; second, the products of its decay during this reaction (tret-butanol, di-tret-butyl ether, methanol, isobutylene and others) are not acceptors of peroxide radicals, i.e. they cannot influence on the rate of oxidation process. HPC cannot be used in this capacity, since the main product of its catalytic decay in the reaction with thiocarbonyls is phenol having antioxidant properties (Table 2).

We studied the ability of the product $(\mathrm{P})$ to break the oxidation chain of isopropylebnzene and ethylbenzene at $333 \mathrm{~K}$. The concentration of product is supposed to be equal to initial concentration of the catalyst. It turned out that all transformation products effectively brake the oxidation (Figures 4-7).

Table 1. Characteristics of inhibition action of thioamide $\left(K_{2}\right)$ (isopropylbenzene, $333 \mathrm{~K}$ ).

\begin{tabular}{cccc}
\hline$\left[A_{2}\right] \times 10^{-2} \mathrm{~mol} / \mathrm{l}$ & $W_{i} \times 10^{7}, \mathrm{~mol} \cdot \mathrm{l}^{-1} \cdot \mathrm{s}^{-1}$ & $W_{0} \times 10^{6}, \mathrm{~mol}^{-1} \mathrm{l}^{-1} \cdot \mathrm{s}^{-1}$ & $f \mathrm{k} \cdot \mathrm{l} \cdot \mathrm{mol}^{-1} \cdot \mathrm{s}^{-1}$ \\
\hline 0.5 & 2 & 7.3 & 52 \\
0.3 & 2 & 9.0 & 77 \\
1.0 & 2 & 6.2 & 33 \\
\end{tabular}

Table 2. Character of inhibitory effect of interaction products of dithiocarbamate $\left(P_{\mathrm{A} 1}\right)$ and thioamide $\left(P_{\mathrm{A} 2}\right)$ with tret-Butyl hydroperoxide (isopropylbenzene, AIBN, $333 \mathrm{~K}, W_{i}=1 \times 10^{7}$, mol l sec.).

\begin{tabular}{|c|c|c|c|}
\hline Products & {$\left[P_{\mathrm{A}}\right] \times 10^{4}, \mathrm{~mol} / \mathrm{l}$} & $W_{02} \times 10^{6}, \mathrm{~mol} \mathrm{l} \mathrm{sec}$ & $f k, 1 \mathrm{~mol} \mathrm{sec}$ \\
\hline \multirow{5}{*}{$\left(P_{\mathrm{A} 1}\right)$} & 2.0 & 1.8 & 2.8 \\
\hline & 3.0 & 1.3 & 2.5 \\
\hline & 4.0 & 1.3 & 1.9 \\
\hline & 8.0 & 0.2 & 3.5 \\
\hline & & & $2.6 \pm 0.5$ \\
\hline \multirow{4}{*}{$\left(P_{\mathrm{A} 2}\right)$} & 1.0 & 0.7 & 21.0 \\
\hline & 2.0 & 0.3 & 45.9 \\
\hline & 3.0 & 0.3 & 30.6 \\
\hline & & & $32.5 \pm 8.9$ \\
\hline
\end{tabular}




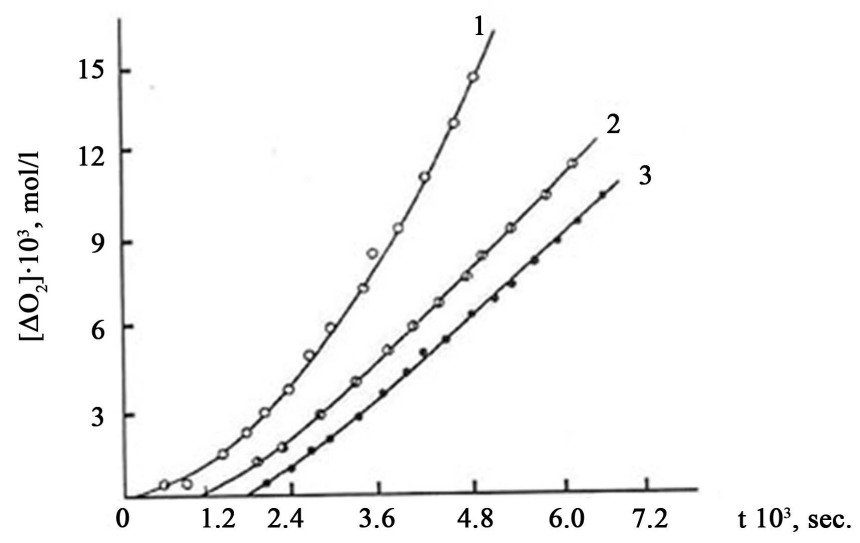

Figure 2. Kinetic curves of autooxidation of ethylbenzene with the presence of $A_{1}$ : lwithout inhibitor; $2-\left[A_{1}\right]=2 \times 10^{-4} \mathrm{~mol} / \mathrm{l} ; 3-\left[A_{1}\right]=5 \times 10^{-3} \mathrm{~mol} / \mathrm{l} ; T=383 \mathrm{~K} ; P_{\mathrm{O} 2}=$ $100 \mathrm{kPa}$.

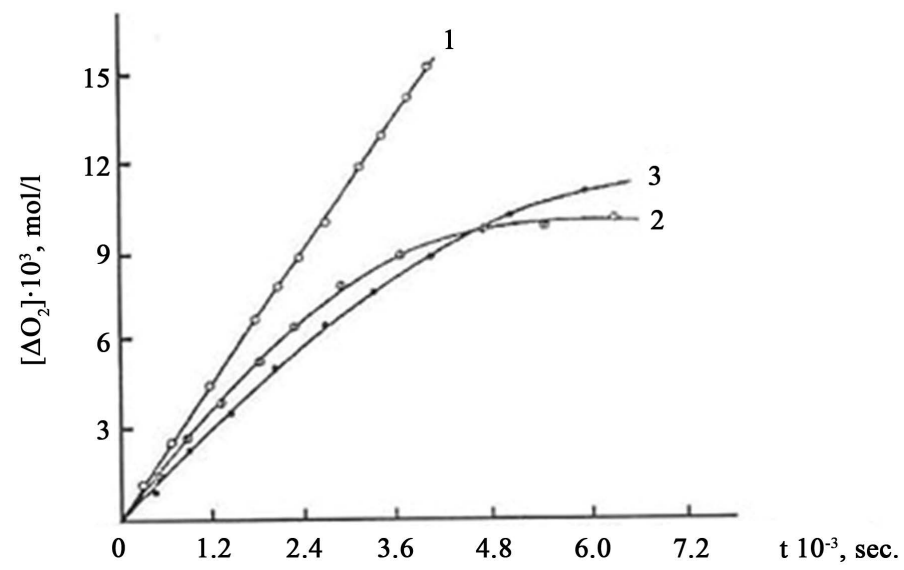

Figure 3. Kinetic curves of oxygen absorption during initiated oxidation of ethylbenzene with $\mathrm{A}_{1} \mathrm{l}$-without inhibitor; $2-\left[\mathrm{A}_{1}\right]=1 \times 10^{-2} \mathrm{~mol} / \mathrm{l} ; 3-\left[\mathrm{A}_{1}\right]=3 \times 10^{-2} \mathrm{~mol} / \mathrm{l}$; $T=337 \mathrm{~K} ;$ AIBN] $=5 \times 10^{-3} \mathrm{~mol} / \mathrm{l}$.

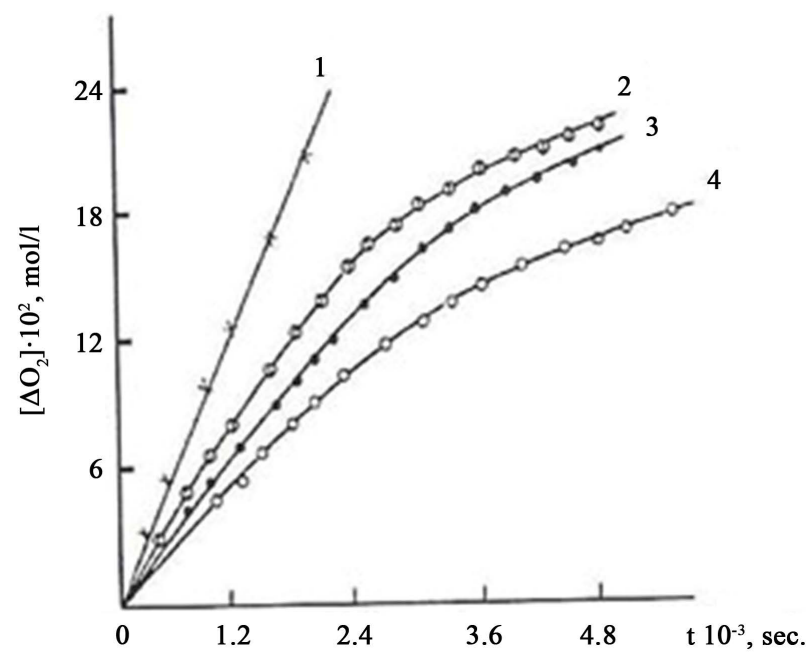

Figure 4. Kinetic curves of initiated oxidation of isopropylbenzene with phenylthioacetomorpholide $A_{2} \mathrm{l}-0 ; 2-0.3 ; 3-0.5 ; 4-1.0$; [AIBN] $=5 \times 10^{-2} \mathrm{~mol} / \mathrm{l}, T=333 \mathrm{~K}$; $\left[A_{2}\right]=1 \times 10^{-2} \mathrm{~mol} / \mathrm{l}$. 


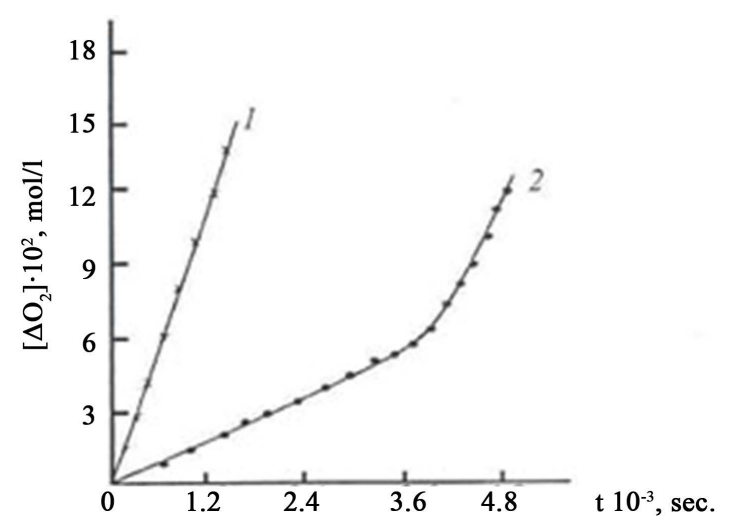

Figure 5. Kinetic curves of initiated oxidation of isopropylbenzene in the presence of interaction products of tret-Butyl hydroperoxide with $A_{1} l$-without inhibitor; $2-P_{\mathrm{A} 1}$ $=4 \times 10^{-4} \mathrm{~mol} / \mathrm{l} ;[$ AIBN $]=5 \times 10^{-2} \mathrm{~mol} / \mathrm{l} ; T=333 \mathrm{~K} ;\left[A_{2}\right]=1 \times 10^{-2} \mathrm{~mol} / \mathrm{l}$.

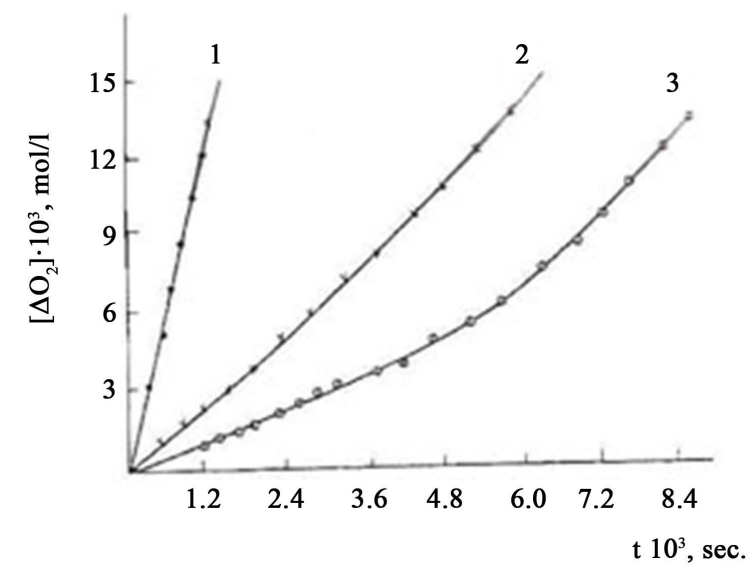

Figure 6. Kinetic curves of oxygen absorption during initiated oxidation of ethylbenzene in the presence of interaction products of tret-Butyl hydroperoxide with $A_{1}$ : lwithout inhibitor; $2-[\mathrm{AIBN}]=5 \times 10^{-2} \mathrm{~mol} / \mathrm{l} ; 3-P_{\mathrm{A} 2}=8 \times 10^{-4} \mathrm{~mol} / \mathrm{l} ; 3-P_{\mathrm{A} 2}=2 \times$ $10^{-4} \mathrm{~mol} / \mathrm{l} ; \mathrm{T}=333 \mathrm{~K}$.

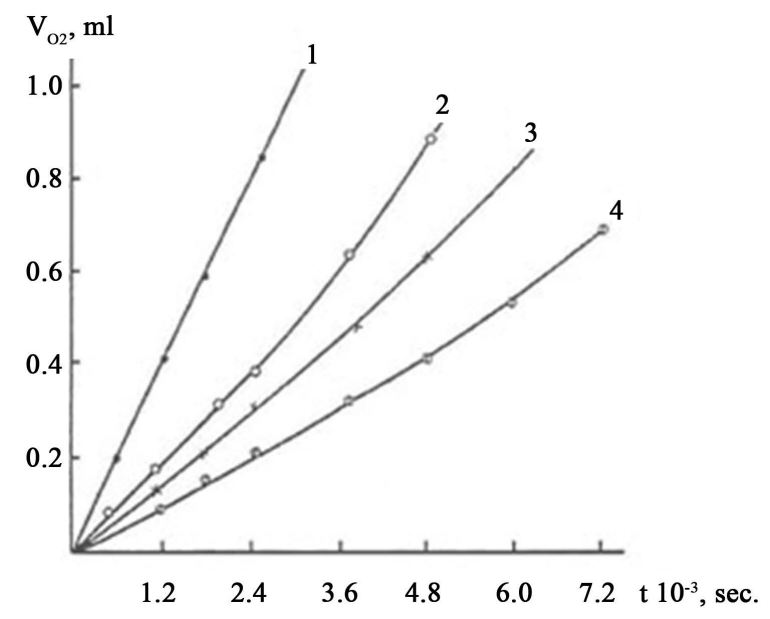

Figure 7. Kinetic curves of oxygen absorption during initiated oxidation of isopropylbenzene in the presence of interaction products of tret-Butyl hydroperoxide with phenylacetomorpholide $\left(A_{2}\right): T=333 \mathrm{~K}$; [AIBN] $=1 \times 10^{-2} \mathrm{~mol} / \mathrm{l}$; l一without inhibitor; $2-P_{\mathrm{A} 2}=1 \times 10^{-4} \mathrm{~mol} / \mathrm{l} ; 3-P_{\mathrm{A} 2}=2 \times 10^{-4} \mathrm{~mol} / \mathrm{l} ; 4-P_{\mathrm{A} 2}=3 \times 10^{-4} \mathrm{~mol} / \mathrm{l}$. 
The value $f k$ was calculated by initial oxidation rate of isopropylbenzene. Limiting speed of oxygen absorption which is reached by the end of braking period, slightly differs from uninhibited oxidation rate. This shows that obtained products are almost completely consumed by the end of braking period, but the other braking products are not formed at noticeable concentrations during experiment.

\section{Conclusions}

Thus, two main conclusions can be made:

1) In value of $f k$ oxidation transformation products of thiocarbonyl can be put in the following order: thioamide >> dithiocarbamate.

2) As an acceptor of peroxide radicals the oxidation transformation products of phenylthioacetomorpholide $\left(P_{\mathrm{A} 2}\right)$ equals to industrial antioxidants (ionyl and other hindered phenols).

\section{Acknowledgements}

Used in this work software package OptimMe for the calculation of kinetic parameters was developed by the support of Science Foundation of "SOCAR" under the grant project ET-27 (15/10/2014) at the Institute of Catalysis and Inorganic Chemistry named after Acad. M.F.Nagiyev.

\section{References}

[1] Kuliev, A.M. (1982) Chemistry and Technology of Additives to Oils and Fuels. M.: Chemistry, 360.

[2] Denisov, E.T., Sarkisov, O.M. and Liechtenstein G.I. (2000) Chemical Kinetics. M.: Nauka. 568.

[3] Patent No. 2239494 (RF) (2004) Oxidation Catalysts of Phenol Compounds Series. (Bogolitsyn, K.G., Popova, N.P., Skrebets, T.E. and Kosheleva, A.E.) BI, 31, 324.

[4] Nasiri, F.M., Efendy, A.J., Melikova, I.G. and Zaytseva, Z.A. (2009) Study of Kinetics of Antioxidant Effect of Carbamate and Thioamide in Oxidation Process of Hydrocarbons. Azerbaijan Chemistry Journal, 1, 62-73.

[5] Denisov, E.T. and Kovalev, T.I. (1993) Oxidation and Stabilization of Reactive Fuels. M: Chemistry, 272.

[6] Denisov, E.T. (1981) Rate Constants of Hemolytic Liquid-Phase Reactions. M.: Nauka, 711. 